\title{
What's in this issue: the new-look Primary Care Respiratory Journal
}

As the UK General Practice Airways Group (GPIAG) meets for its Annual Conference to celebrate its 20th anniversary, it gives us great pleasure to welcome you to the new-look Primary Care Respiratory Journal (PCRJ) - the official journal of the GPIAG and the International Primary Care Respiratory Group (IPCRG).

As announced earlier this year, ${ }^{1}$ the $P C R J$ is now being published by Sherborne Gibbs. When we entered into discussion with our new publishers last autumn, it was clear that the future development of the Journal required several initiatives: firstly, a new updated design for the hard copy journal to attract new readers; secondly, the establishment of free worldwide online access to $P C R J$ papers without charge for readers or authors; and thirdly, worldwide marketing of the $P C R J$.

This new-look $P C R J$ is the result. Averil Maskew and Helen McDonnell of Sherborne Gibbs have been tremendously patient with us as we have striven to develop a new journal design. The process has involved the production of a new PCRJ logo, and considerable sharing of ideas on what the new journal should look like. In essence, our aim has been to maintain the wellrespected academic look of the $P C R J$ whilst at the same time keeping it interesting and broadening its appeal. This has involved the judicious use of colour throughout, a change in font and overall layout, and a change to the News section which we have altered to give it a more 'journalistic' look. We have also initiated a clearer system of flagging up related articles within the same issue; thus, the paper by Iversen et al. ${ }^{2}$ is clearly flagged at the beginning of the linked editorial by David Chinn, ${ }^{3}$ and vice versa. We do hope you like the new design, and we are extremely grateful to Averil and Helen for their expertise.

The new $P C R J$ website, www.thepcrj.org, is already proving to be a great success, with nearly $50 \%$ of referrals being directed from PubMed through the linkout system. The site has direct links to and from Medline/Index Medicus, SCOPUS, and Embase, and provides access to the current journal issue, all previous $P C R J$ issues, and access to articles 'in press' which have already been accepted for publication. We have thus made the online version of the $P C R J$ available, free of charge, to healthcare professionals throughout the world. This will be of inestimable benefit to the worldwide profile of the Journal, and of particular benefit to our clinical and academic colleagues in the IPCRG and in developing countries. Free online access will have several other benefits, the most important of which is the increased likelihood of PCRJ papers being read and cited; this will in turn improve our chances of a successful application for a citation index, which we hope to apply for in the near future.

The establishment of the new $P C R J$ website would not have been possible without the freedom provided by the new publishing agreement with Sherborne Gibbs, for which we are very grateful. We are also enormously grateful to Lynn Danzig who (along with MLL) set up the new website; Lynn is continuing to develop the site, so have a look and let us know your comments and suggestions by contacting us at info@gpiag.org.

To celebrate the 20th anniversary of the GPIAG, we present in this issue a commemorative review of the GPIAG and its achievements over the last 20 years. ${ }^{4}$ The author list includes most of the six founding members of the GPIAG, the current Committee Chairman and Chief Executive, and all previous GPIAG Committee Chairmen. The list of GPIAG achievements over the last 20 years is considerable: the development of primary care respiratory research and the establishment of the GPIAG chair in Aberdeen; the extensive research output from GPIAG members; the development of the PCRJ; GPIAG representation on hational and international guideline committees on respiratory disease and allergy; numerous educational initiatives; the championing of primary care respiratory medicine; facilitating the development of special interest primary care practitioners in respiratory disease, be they GPs (GPwSIs) or other practitioners (PwSIs) with a special interest; and the ability to provide authoritative opinion on primary care respiratory disease and allergy for the benefit of government and healthcare policy makers. The GPIAG is proud to celebrate its 20th anniversary.

The UK GPIAG was the first national primary care respiratory interest group in the world, and since 1987 many other countries have followed suit with the establishment of their own special interest respiratory groups. This process culminated in the formation of the International Primary Care Respiratory Group (IPCRG) following the GPIAG International Conference at Robinson College, Cambridge, in 2000. The IPCRG now acts as an international umbrella organisation for all national primary care respiratory groups. We are therefore delighted to include in this issue a review paper on the importance of the GPIAG from an international perspective written by Ron Tomlins (IPCRG Treasurer) and Sian Williams (IPCRG Executive Officer). ${ }^{5}$

As the GPIAG gathers for its 20th anniversary, it is important to note that it is not the only organisation celebrating 20 years' impact on primary care respiratory medicine. Education for Health, formerly the National Respiratory Training Centre (NRTC), also celebrates its 20th anniversary this year, and many of its members are with us in Keele to make it a joint celebration. The impact of the NRTC, ever since its founding by Greta Barnes in 1987, has been enormous. The advent of formalised training in 
respiratory disease for practice nurses transformed primary care management of asthma in the UK, and the organisation now provides training in COPD, allergy, and other disease areas, not just in the UK but internationally. Therefore, in this context, we publish in this issue a review article by Martyn Partridge - who was a Trustee of the NRTC for many years - on developments in asthma management over the last 20 years. ${ }^{6}$ In addition, Monica Fletcher (Chief Executive of Education for Health) presents a Discussion paper on the importance of continuing education for healthcare professionals ${ }^{7}$ in the context of a recently published study which confirms that continuing professional education can alter patient outcomes. ${ }^{8}$

We include in this issue an excellent review paper by Neil Barnes on the relative similarities and differences between the different inhaled steroids. ${ }^{9}$ We also have several original research articles, ${ }^{2,10-12}$ a discussion paper on the required terms of employment for GPs (GPwSIs) and practitioners (PwSIs) with a special interest in respiratory disease, ${ }^{13}$ a case report of bronchial aspiration, ${ }^{14}$ and a letter on the importance of history-taking when we see the parents of children who may have preschool asthma. ${ }^{15}$ The paper by Woodcock et $a /^{12}$ is of particular note: it presents an analysis of data from the previously-reported GOAL study, but in this paper the authors have assessed the magnitude of change in single specific asthma endpoints as opposed to the composite measure of control which was used in the first GOAL analysis.

Following the $P C R J$ 's acquisition of Medline listing in February $2006^{16}$ the Journal has had a 30\% increase in paper submissions, and this follows a three-fold increase in the 18 months prior to that. All submitted papers are sent out to two referees who provide double-blind peer review under the auspices of an assigned editor who is responsible for the fate of that particular paper. We are enormously grateful to all the authors who have contributed to the PCRJ over the years, and we hope that they continue to do so. In addition, we are indebted to our referees who so assiduously provide excellent peer-review of submitted papers.

We do hope that you like the new-look PCRJ. Let us know what you think by writing to us at info@gpiag.org. If you aren't a member of the GPIAG, and you would like to receive a bimonthly hard copy print version of the Journal, you can register for GPIAG membership on the GPIAG website at www.gpiag.org. Alternatively, you can see all current and past issues of the Journal at www.thepcrj.org.

\section{References}

1. Levy ML. What's in this issue. Prim Care Resp J 2007;16(1):1-3. doi:10.3132/ pcrj.2007.00010

2. Iversen L, Hannaford PC, Godden DJ, Price DB. Do people self-reporting information about chronic respiratory disease have corroborative evidence in their general practice medical records? A study of intermethod reliability. Prim Care Resp J 2007;16(3):162-8. doi:10.3132/pcrj.2007.00013

3. Chinn DJ. Can general practitioner-held data substitute for self-reporting of respiratory morbidity and health care utilisation? Prim Care Resp J 2007;16(3):130-1. doi:10.3132/pcrj.2007.00031

4. Levy ML, Stephenson P, Barritt P et al. The UK General Practice Airways Group
(GPIAG): its formation, development, and influence on the management of asthma and other respiratory diseases over the last twenty years. Prim Care Resp J 2007;16(3):132-9. doi:10.3132/pcrj.2007.00042

5. Tomlins R, Williams S. The impact of the UK General Practice Airways Group (GPIAG) - an international perspective. Prim Care Resp J 2007;16(3):140-4. doi:10.3132/pcrj.2007.00037

6. Partridge MR. Asthma: 1987-2007. What have we achieved and what are the persisting challenges? Prim Care Resp J 2007;16(3):145-8. doi:10.3132/pcrj. 2007.00039

7. Fletcher M. Continuing education for healthcare professionals: time to prove its worth. Prim Care Resp J 2007;16(3):188-90. doi:10.3132/pcrj.2007.00041

8. Sheikh A, Khan-Wasti S, Price D, Smeeth L, Fletcher M, Walker S. Standardized training for healthcare professionals and its impact on patients with perennial rhinitis: a multi-centre randomised controlled trial. Clin Exp Allergy 2007; 37(1):90-9.

9. Barnes N. The properties of inhaled corticosteroids: similarities and differences. Prim Care Resp J 2007;16(3):149-54. doi:10.3132/ pcrj.2007.00038

10. Lange $\mathrm{P}$, Rasmussen FV, Borgeskov $\mathrm{H}$ et al. The quality of COPD care in general practice in Denmark: the KVASIMODO Study. Prim Care Resp J 2007; 16(3):174-81. doi:10.3132/pcrj.2007.00030

11. Frank TL, Hazell ML, Linehan MF, Morris JA, Frank PI. The estimated prevalence of chronic obstructive pulmonary disease in a general practice population. Prim Care Resp J 2007;16(3):169-73. doi:10.3132/pcrj.2007.00028

12. Woodcock A, Bagdonas A, Boonsawat W, Gibbs MR, Bousquete J, Bateman E on behalf of the GOAL Steering Committee \& Investigators. Improvement in asthma endpoints when aiming for total control: salmeterol/fluticasone propionate versus fluticasone propionate alone. Prim Care Resp J 2007;16(3): 155-61. doi:10.3132/pcrj.2007.00043

13. Gruffydd-Jones K, Stephenson P, Levy ML on behalf of the GPIAG Working Party. What standards and terms of employment should respiratory practitioners with a special interest expect from an employing organisation? Prim Care Resp J 2007;16(3):182-7. doi:10.3132/pcrj.2007.00032

14. Ripley DP, Henderson AK. A case of bronchial aspiration: the importance of early diagnosis and clinical suspicion. Prim Care Resp J 2007;16(3):191-3. doi:10.3132/pcrj.2007.00029

15. Ostergaard MS, Prahl P. Diagnosis of preschool asthma: parents' comments and typical phrases may ease history-taking. Prim Care Resp J 2007;16(3):194-5. doi:10.3132/pcrj.2007.00035

16. Levy ML, Stephenson P, Griffiths $C$ et al. Primary Care Respiratory Journal is awarded full Medline/Index Medicus listing. Prim Care Resp J 2006;15(3):136-8. doi:10.1016/j.pcrj.2006.04.003

\section{Paul Stephenson}

Deputy Editor PCRJ, The Christmas Maltings and Clements Practice, Haverhill, Suffolk, UK

\section{Chris Griffiths}

Assistant Editor PCRJ, Professor of Primary Care, MRC Asthma UK Centre in Allergic Mechanisms of Asthma, Centre for General Practice and Primary Care, Institute for Community Health Sciences, Queen Mary's School of Medicine and Dentistry, Barts and the London Hospitals, London, UK

\section{CP Onno van Schayck}

Assistant Editor PCRJ, Professor of General Practice, Care and Public Health Research Institute (CAPHRI), University of Maastricht, The Netherlands 


\section{Aziz Sheikh}

Assistant Editor PCRJ, Professor of Primary Care Research and Development, Allergy and Respiratory Research Group, Division of Community Health Sciences: GP Section, University of Edinburgh, UK

\section{Patricia Bryant}

Publication Manager, GPIAG

\section{*Mark L Levy}

Editor-in-Chief PCRJ, Senior Clinical Research Fellow, Allergy and Respiratory Research Group, Division of Community Health Sciences: GP Section, University of Edinburgh, UK.

*Correspondence:

c/o GPIAG, Smithy House, Waterbeck, Lockerbie, DG11 3EY, UK. Tel: +44 (0)1461 600639 Fax: +44 (0)1461 207819 E-mail: marklevy@animalswild.com

Available online at http://www.thepcrj.org 